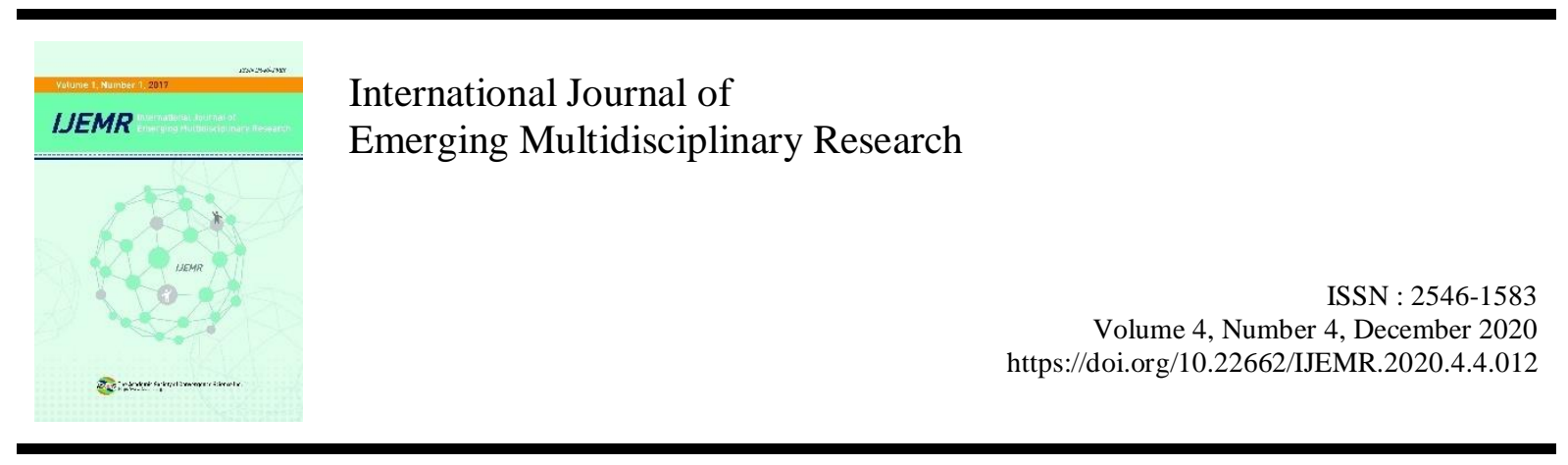

\title{
Homelessness as a Social Problem
}

\author{
Guozhong $\mathbf{L i}^{\mathbf{1}}$ \\ ${ }^{1}$ Dept. of Management Science and Information System, Faculty of Management and Economics, Kunming \\ University of Science and Technology, 650093, China
}

\begin{abstract}
Background/Objectives: This study is a study of solutions to homeless social problems. Methods/Statistical analysis: In this research, we proceeded with research on solutions to the homeless problem through a case study of previous research. Findings: Through this research, we looked at the problems of homelessness and their causes, and tried to propose solutions. Improvements/Applications: The solutions presented in this study may help solve the homeless.
\end{abstract}

\section{Keyword}

Homeless, social problem, solution, response plan, homeless cause

\section{INTRODUCTION}

Homelessness is not a problem that is unique to modern day society. It is a phenomenon that has been with society throughout the history of recorded time [1]. What has changed over time, however, is how one have conceived of homelessness a s a social problem; the homeless have been viewed as more or less deserving of assistance at different times and in different places in history.

Guest (1997) discusses notions of deserving and undeserving in the context of residual (undeserving) and institutional (deserving) models of social welfare[2]. Current social policy discourse is influenced by both the institutional and residual models of social welfare. There is an interactional relationship between how policy makers and society as a whole conceive of social problems.

Both influence the other and mutually shape the direction of social policy in Canada. When it comes to the social problem of homelessness, some of the homeless are seen to be deserving, and others are deemed to be undeserving of assistance.

In order to understand something the nature of homelessness, what contributes of it and what we should do about it, it makes sense that we could find out how the public conceives of homelessness as a social problem, as their attitudes impact upon those who are developing policy and interventions to combat the problem.

Knowing something of the public's attitudes

\footnotetext{
Corresponding author : Guozhong $\mathbf{L i}$

narin2017@kust.edu.cn

- Manuscript received October 23, 2020.

- Revised November 14, 2020 ; Accepted November 27, 2020.

- Date of publication December 31, 2020.

(C) The Academic Society of Convergence Science Inc.

2546-1583 @ 2017 IJEMR. Personal use is permitted, but republication/redistribution requires IJEMR permission.
} 
toward homelessness provides support, or conversely, rationale for not supporting the development of policy within a particular ideological framework[3].

Much of the rhetoric of the popular media focuses on how many are in fact homeless all over the world. When we think about what is and what is not a social problem, we have a need to know how widespread that problem is, and how many people it affects, in order to justify developing an intervention to address the issue[4]. The notion of prevalence is germane to understanding that homelessness is a social problem.

Leslie Pal (1997) argues that the "severity" of a problem is a necessary aspect of problem definition. The acknowledgement of a problem "... often gets connected to the incidence of the problem in the sense of how different groups in the population are affected" [5].

Secondly, numbers are what sells, in both the media and in the political sphere; therefore, society ha made prevalence a relevant consideration when defining homelessness as a problem. However, prevalence simply tells us that homelessness is widespread. Understanding how it is that we conceive of the problem (what it is about; what we should do about it; and how we come to develop personal theories and ideas about the nature of the problem) is key to knowing how to address the issue of homelessness.

What is paramount to understanding our conception of the problem of homelessness is the notion of attitudes. One can never truly "know" what homelessness is about, because it is such an amorphous construct, but one can "know" is how one conceives of it as a problem.

If one can discern something of society's attitudes, what it is and what one should do about it, one can understand something how one can develop theories of the nature of homelessness. Such knowledge about how one construct theories about homelessness informs policy makers. Effective policies are the product of a particular understanding about what one thinks homelessness is and what one should do about it [3].

The purpose of this study is to understand how individuals conceive the notion of homelessness. Also it aims to understand the relationship between what people think homelessness is about and what should be done about it.

\section{Statement of the Problem}

1. What are the factors that contribute to an individual's beliefs to what homelessness is?

2. What are the manifesting characteristics that define what homelessness is?

3. What are the intervening actions that could help address homelessness as a social problem?

\section{REVIEWER OF RELATED LITERATURE}

There are extensive descriptions of what contributes to homelessness and almost as considerable in its depiction of appropriate responses to the problem.

However, what is being studied and written about in agencies, institutions and by academics does not parallel what is being done in the public arena to combat the problem. Papers, recommendations and dialogue about homelessness have been prominent in the social policy arena for decades[3].

\section{A. What is Homelessness?}

It is not possible to enter into a discussion about the nature and breadth of homelessness without first considering the diverse and sometimes conflicting conceptual definitions of homelessness that exist in the literature and in the realm of policy-making and practice in communities.

How and with what parameters one conceives of "homelessness' as a problem of issue requiring attention is inextricably linked to one's definition of the problem. "Inevitably, government policy as well as the literature on homelessness is politically or ideologically motivated" [6].

Most simply put, there is a direct correlation (or relationship between how we, both individually and collectively as a society, define problems, and what we do about them. It is indiscriminate to consider solutions to problems such a s homelessness without being aware of one's underlying beliefs about what homelessness is and how that belief system is constructed. It does not seem possible to develop comprehensive solutions to a problem without an intentional exploration of the belief system that underlies the issue.

"Public policies, as guides to action, may be seen as hypothetical solutions to some perceived problem. The definition of the problem, therefore, is the heart of the policy..." [5].

How society, within and outside of the domain of policy-development, have come to understand homelessness and its component parts dictates our action or inaction to address the issue.

One of the questions that seems to be on everyone's minds and is played out in the media is: "How many people in our communities are homeless?" what is less frequently discussed, however, is what it is we mean when we talk about homelessness [3].

Existing literature provides varied and sometimes conflicting definitions of homelessness. The Oxford Dictionary defines the work "homeless' as "lacking a dwelling place," a definition that is viewed as somewhat simplistic to some and restrictive in its scope to others [7]. "...this definition [is] both 
simplistic and restrictive, but is is the basic common denominator of all the definitions in the literature. It is the most clear and precise definition to describe those individuals who are without a home. What follows is an exploration and critique of the literature in this area with particular attention paid to the thesis of this research [3].

The broader of the definitions in the literature is illustrated by Oberlander and Fallick(1988) who posit that "homelessness... is the absence of a continuing or permanent home over which individuals or family groups have personal control and which provides the essential needs of shelter, privacy and security at an affordable cost, together with ready access to social and economic public services"[9].

This definition is the most broad and allencompassing of the definitions...reviewed, most specifically because of it6s reference to access to community services [3].

A common conceptual theme in the literature relates to the possibility of homelessness, or marginality, as is demonstrated by Gerald Daly. Daly regards his definition of homelessness to be more liberal than most:

People are considered homeless if they lack adequate shelter in which they are entitled to live safely. At the extreme, they are sleeping rough. Others live under a roof but their accommodation is lacking in safety, security, or basic amenities (e.g. heat, water, bathroom).

Homelessness is a fluid and elusive concept. People who lace secure accommodation frequently change location, status, and living arrangements. Their deprivation depends on the extent to which the absence of shelter is combined with social isolation and economic poverty[6].

Burt makes the distinction between the "'literally homeless' - that is, living on the streets or in shelters. The remainder are considered at 'imminent risk' of literal homelessness - that is, if their current precarious hosing arrangements fail, or if an institutional stay comes to a predictable end, they have neither prospects nor resources to keep themselves from literal homelessness" [8].

Such a definition differentiates between those who are homeless and those who are not, providing a definitively clear and ideologically-bound reference point. Such a definition is clearer that Oberlander and Fallick's (1988), both from a policy and client perspective; it legitimizes by making the distinction between two constructions that are somewhat theoretically and most definitely operationally different[9].

Emmanuel and Suttor further divide the literally homeless into two distinctive categories:

Homelessness is a complex issue. The definition encompasses many situations more than just people on the streets. It includes visibly homeless people on the streets or using hostels; hidden homeless people living in illegal "squats" or temporary accommodation; and people at risk of becoming homeless because they pay large shares of their income on rent, or live in overcrowded, unsafe, or insecure housing[9].

Although Emanuel and Suttor (1998) overtly label those who are at risk of becoming homeless as included it eh definition of "homelessness," Oberlander and Fallick (1988) and Daly (1996) imply inclusion of this sub-group of individuals by virtue of the fact that they speak to the lack of continuity and adequacy of existing shelter as being a necessary component of homelessness.

As such, Emanuel and Suttor's (1998) definition most succinctly and clearly demonstrates the major themes of the literature on the subject of a definition of homelessness[10].

O'Reilly-Fleming considers homelessness from a "person-centered" perspective [11]. "The only person who is in a position to judge whether they are homeless or not, and in need of shelter or not, is the individual who sees themselves in this way" [11].

A "person-centered" perspective of homelessness, however, is not useful to policy makers ho are required to develop services and programs within a particular framework[3].

\section{B. Prevalence}

How one conceives of the construct of homelessness directly affects the method employed to determine the prevalence of homelessness in a particular geographic area. What is most common, in the literature, however, is the discussion and critique of the methods employed to count the numbers of homeless individuals.

Furthermore, the focus of the literature on policy initiatives is on implementing strategies that will contribute to both preventive and residual solutions to homelessness less so than determining the numbers of homeless[3].

Cordray and Pion provide a way to understand the wide variance between studies that estimate the numbers of homeless. "These include differences in conceptual definitions of homelessness (i.e. what is included in the definition of homelessness; difference $s$ in operational definitions (i.e. what are the specific characteristic $s$ that define a particular person as homeless); differences in intended uses for the information (i.e. why the data is being collected); and differences in methodologies (i.e. how the enumeration is conducted)" [12].

How one comes to understand both the implicit and explicit rationale for defining a concept such a homelessness is related to a particular ideological stance; as such, a study framed to "count" or estimate numbers of homeless individuals is bound up with 
ideological and $/ \mathrm{r}$ politically motivated thinking, whether intentional or not. It is important to know how many individuals are homeless, then it begets the question: Does prevalence categorically define something as a problem? Do we need to know that a certain number of our population is homeless in order to develop interventions?[3]

\section{Contributing Factors}

How one conceives of the nature of homelessness is implicit in the use of language to describe what contributes to homelessness. Whether one describes the "causes" or the "contributing factors" of homelessness has implications for the attribution of responsibility.

Focus group participants used both terms to describe their understanding about what it is that leads to homelessness; as such, in the focus groups, I used both "contributing factors" and "causes" to respond to their description of etiology, recognizing that there are multiple determinants of homelessness [3].

What re the contributing factors that can lead to homelessness? Oskamp (1990) and Lee et al.(1992) report that a victim-blaming approach to understanding the etiology of homelessness emphasizing individual psychology is prominent in the literature[13, 14].

This approach has neglected to consider the contributing factors that lead to homelessness, such as poverty, relationship breakdown, unemployment, housing supply, poor education, changes in mental health policy, racial discrimination and so on $[15,16]$.

It is important to also consider "individual problems as both consequences and causes of homelessness, dynamics of entry to and exits from homelessness, and pertinent social policy at both micro and macro levels"[17]. For this reason, a threefold model of homelessness will be employed considering factors at the individual level, social factors and the socio-economic context $[16,17]$

\section{Individual-Level Predictors}

"Individual-level predictors of homelessness might be loosely categorized into individual characteristics, experiences and behaviors. Individual characteristics include youth...ethnicity...status as a family, and disabilities, such as poor health and mental illness" [17].

The most significant individual experiences that lead to homelessness may be those that can lead to housing loss, such as eviction[18], those that reduce financial resources such as job loss or underemployment[19] and those that lead to loss of social assistance benefits.

"The most commonly shared feature of almost all homeless people is that they are very poor" [20] and the homeless are among the poorest of the poor, living on less than 40 percent of the official poverty line[16], "social groups that re over-represented among the poor (persons with disabilities, single parents, certain ethno-racial groups) are likewise over-represented among the homeless" [10].

\section{E. Social Factors}

"McChesney (1987) suggests that people's social network serves as a safety to prevent them from falling into homelessness" [21]. Those who have support systems in place will have other resources that they are able to access prior to or instead of moving towards homelessness.

There have been several studies that have found that homeless people often lack social supports, especially those that offer close ties with family members[16].

It is important to consider the significant role that social supports play in determining whether or not an individual becomes homeless; however, the relationship between homelessness and social supports is not uni-directional. Social supports may contribute to or avert a situation where someone finds themselves living without a home[17].

Blasi (1990) makes reference to the "disaffiliation" that is part of the experience of life for most homeless individuals[22]. He contends that, in order to understand the multidimensional relationship of social factors to homelessness, it is most helpful to consider the resources that are available to people over time:

Some people have, in fact, no social resources. Many children who grow up in institutions or foster care are simply discharged to the streets upon reaching the age of majority.

In other cases, family and friends are so poor thatwhatever love, affection, and affiliation exists-there are not enough resources, even when shared by loving family and friends, to keep all the network members off the street. The process here is not one of disaffiliation, but of exhaustion of meager resources, often the inevitable consequences of extreme and persistent poverty[22]

\section{F. Socioeconomics}

Socioeconomics is about people and money. The term "economics" makes a statement about a financial situation, while inclusion of "socio" as a prefix considers the fact that society is involved and affected by economics. We discuss socioeconomics in the context of dialogue about "having enough" when it comes to the "have-nots" and those who are impoverished in society[3].

There is an obvious relationship between homelessness and socioeconomics. Kiesler(1991) 
claims that homelessness is primarily about lack of economic resources.

However, Shinn and Weitzman indicate that "research on macroeconomic factors has been least well connected to individual outcomes' [23]. Morris argues a macro-approach to understanding the relationship between the individual and the structural when it comes to socioeconomic factors:

The necessary relationship between social structure and individuals means that, when structural factors leave some at a disadvantage, those individuals with particular types of personal problems will find themselves most vulnerable and pushed further down the queue in the competition for scarce resources.

It may tell us something about ourselves and our culture to look at how we relegate individuals to these bottom rungs of the socioeconomic ladder, at how they are treated once they arrive there and how long they are allowed to stay[24].

Socioeconomic factors include but are not limited to situations that are affected by employment and economic sustenance. The relationship between employment and homelessness can be understood as both an individual-level predictor of homelessness and as being related to socioeconomic factors[3].

The state of homelessness is not caused by any one factor; it is the result of the interrelationship of many variables from the individual to the societal systems. "Homelessness is the result of some combination of problems in getting enough income, finding and keeping housing that one can afford, as well as other key factors.

These other factors may include family breakdown, lack of friends and relatives who provide informal help, meta illness, substance abuse and so on" [10].

\section{Conclusion}

Many previous studies and reports discuss measures for homeless solutions. In particular, there are many homeless people who are unemployed, alcoholic, unpaid rent, abandoned from selfsufficiency, and divorced.

As a way to solve the homeless problem, you can support it through food support, shelter, health care, treatment center, etc., and it can be solved after the fact rather than the fundamental solution. This is very important for the homeless to be self-reliant,

Big Reason, a magazine published in the UK, is that homeless salespeople sell and share revenue to help homeless people become independent. In South Korea, there is The Big Issue Korea.

The city of Birmingham in the United Kingdom has formed a council to build partnerships with various individuals and groups to be homeless. In particular, he announced a new policy model, benchmarking the success stories of St. Basils' Youth Homelessness
Prevention Service.

However, there is no one-by-one solution yet. Many researchers and practitioners are trying to solve the homeless problem, but problems such as related policies, legal systems, and culture have failed to make a big difference.

I hope that there will be a plan that can solve various home-rising problems that can be realized more realistically.

\section{REFERENCES}

[1] Geremek, B. (1994). Poverty: A history. Blackwell.

[2] Guest, D. T. (2013). The emergence of social security in Canada. ubc press.

[3] Jeffery, H. E. (1999). The construction of homelessness as a social problem: Linking contributing factors, mediating factors and interventive strategies.

[4] Posavac, E. J. (2015). Program evaluation: Methods and case studies. Routledge.

[5] Pal, L. A. (1997). Beyond policy analysis. Scarborough, Nelson.

[6] Daly, G. (1998). Homeless. Policies, strategies, and lives on the street. Capital \& Class, 22(2), 167-169.

[7] Allen, R. E. (Ed.). (1985). The Oxford dictionary of current English. Oxford University Press.

[8] Baumohl, J. (Ed.). (1996). Homelessness in America. Greenwood Publishing Group.

[9] Oberlander, H. P., \& Fallick, A. L. (1988). Homelessness and the Homeless: Responses and Innovations. Centre for Human Settlements, University of British Columbia.

[10] Emanuel, B., Suttor, G., \& Golden, A. (1998). Background paper for the homelessness action task force. Homelessness Action Task Force.

[11] O'Reilly-Fleming, T. (2000). Down and out in Canada: homeless Canadians. Canadian Scholars' Press and Women's Press.

[12] Straw, R. B. (1995). Looking behind the numbers in counting the homeless: An invited commentary.

[13] Oskamp, S.(1990). The editor's page. Journal of Social Issues, 46, (4). https://doi.org/10.1111/j.15404560.1990.tb01930.x

[14] Lee, B. A., Lewis, D. W., \& Jones, S. H. (1992). Are the homeless to blame?: A test of two theories. The Sociological Quarterly, 33(4), 535-552.

[15] Deacon, A., Vincent, J., \& Walker, R. (1995). Whose choice, hostels or homes? Policies for single homeless people. Housing Studies, 10(3), 345-363.

[16] Rowland, R. C. (1991). The plight of the homeless: An overview of the issues in helping the homeless in the United States. Natl Textbook Co.

[17] Shinn, M., Knickman, J. R., \& Weitzman, B. C. (1991). Social relationships and vulnerability to becoming homeless among poor families. American psychologist, 46(11), 1180.

[18] Shinn, M., \& Weitzman, B. C. (1990). Research on homelessness: An introduction. Journal of Social Issues, 46(4), 1-11.

[19] Greer, N. R. (1986). The Search for Shelter. American Institute of Architects Order Dept., 9 Jay Gould Court, PO Box 753, Waldorf, MD 20601. 
[20] Emanuel, B., Suttor, G., \& Golden, A. (1998). Background paper for the homelessness action task force. Homelessness Action Task Force.

[21] McChesney, F. S. (1987). Rent extraction and rent creation in the economic theory of regulation. The Journal of Legal Studies, 16(1), 101-118.

[22] Blasi, G. L. (1990). Social policy and social science research on homelessness. Journal of Social Issues, 46(4), 207-219.

[23] Kiesler, C. A. (1991). Homelessness and public policy priorities. American Psychologist, 46(11), 1245.

[24] Morris, J. M. (1997). Chronic homelessness among working-age adults: Personal problems and public assistance. Journal of Social Distress and the Homeless, 6(1), 57-69. 